\title{
Effects of calcium lactate and ascorbic acid on osmotic dehydration kinetics and metabolic profile of apples
}

\author{
Silvia Tappi ${ }^{a, *}$, Maria A. Mauro ${ }^{b}$, Urszula Tylewicz $^{a}$, Nicolò Dellarosa $^{a}$, \\ Marco Dalla Rosa ${ }^{a, c}$, Pietro Rocculi ${ }^{a, c}$ \\ a Department of Agricultural and Food Sciences, University of Bologna, Cesena, Italy \\ b Department of Food Engineering and Technology, São Paulo State University (UNESP), São José do Rio Preto, Brazil \\ c Interdepartmental Centre for Agri-Food Industrial Research, University of Bologna, Cesena, Italy
}

\section{A R T I C L E I N F O}

\section{Article history:}

Received 14 July 2016

Received in revised form 4 January

2017

Accepted 26 January 2017

Available online 16 February 2017

Keywords:

Minimally processed apples

Sucrose

Mass transfer

Solutes impregnation

Endogenous metabolic activity

Respiration rate

\begin{abstract}
A B S T R A C T
The influence of the addition of calcium lactate (CaLac) and ascorbic acid (AA) to sucrose (Suc) osmotic solutions on osmotic dehydration kinetics and endogenous metabolic heat production of apple tissue was evaluated. Our research goal was to characterize mass transfer and endogenous metabolic phenomena of the tissue to obtain minimally processed apples. The presence of CaLac and AA in solution affected the mass transfer of water and solutes, which was attributed to the changes in the cellular structure and thus to spaces available for solute transport. The metabolic heat production in samples treated in sucrose solutions was slightly lower than in untreated samples, and it was further reduced with CaLac addition. However, samples impregnated with AA exhibited a higher heat production due to a metabolic response of the tissue to AA treatment. When combined with CaLac, the heat production decreased to a level lower than untreated samples, except for those that were treated for 120 and $240 \mathrm{~min}$ (higher impregnation), achieving the highest heat production values. These results confirm previous findings, suggesting that AA solution can promote a stress response on specific fresh-cut vegetable tissues, as well as an increase of their endogenous metabolic activity, as confirmed by the higher $\mathrm{O}_{2}$ consumption observed with the head space gas determination.
\end{abstract}

(c) 2017 Institution of Chemical Engineers. Published by Elsevier B.V. All rights reserved.
1. Introduction

Osmotic dehydration (OD) of plant foods is a concentration process in which water is removed from the plant tissue to a hypertonic solution and solutes flow from the solution into the food. The water removal from fresh plant tissues is usually greater than the solute gain because of the semi-permeability of the cell membranes (Ahmed et al., 2016). OD depends on the tissue structure, which changes according to the environment and structure itself. Consequently, the complexity of structures and properties of plant tissues are challenging factors for optimizing processes and designing equipment (Fernandez et al., 2004).
In addition to the advantages of lowering the water content, the OD modifies the food composition. As a result, impregnation of desirable solutes can improve the nutritional and sensorial characteristics (Akbarian et al., 2014; Silva et al., 2014b; Barrera et al., 2004). OD is becoming popular as a technique for obtaining minimally processed fruits, improving their quality and stability, and most recently, this method has been combined with other innovative techniques, such as pulsed high electric field, high hydrostatic pressure, ultrasound, centrifugal force, vacuum and gamma and irradiation, which can enhance its efficiency and improve the quality of the final products (Ahmed et al., 2016).

\footnotetext{
* Corresponding author.

E-mail address: silvia.tappi2@unibo.it (S. Tappi).

http://dx.doi.org/10.1016/j.fbp.2017.01.010

0960-3085/@ 2017 Institution of Chemical Engineers. Published by Elsevier B.V. All rights reserved.
} 
The type of solute used in the osmotic solution is a fundamental issue, because beyond affecting the dehydration kinetics and process cost, it impacts the organoleptic and nutritional properties of the final product. Sucrose (Suc) is considered by many authors to be the optimal osmotic agent because it is associated with a higher efficiency than glucose (Saputra 2001), reducing enzymatic browning and aroma losses (Cortellino et al., 2011; Qi et al., 1998; Lenart, 1996).

OD with calcium in solution has been used to increase the firmness of plant tissue and enhance the process efficiency, restricting the sugar gains and increasing the water losses (Ferrari et al., 2010; Mavroudis et al., 2012; Pereira et al., 2006). Calcium can reinforce cell walls by cross linking pectic polymers and is thus able to reduce damage from dehydration (Pereira et al., 2006). At the same time, when the concentration increases or as the treatment proceeds, damage to cell membranes may occur, as reported by Anino et al. (2006). Moreover, calcium has been used in osmotic solutions as a method for obtaining nutritionally fortified products that can increase consumer intake (Silva et al., 2014b; Barrera et al., 2004).

The addition of ascorbic acid (AA) to the osmotic solution has been used to reduce enzymatic browning (Robbers et al., 1997; Lenart, 1996) and compensate for the loss of ascorbic acid in fruits during dehydration (Guiamba et al., 2016; Ramallo and Mascheroni, 2010).

Various solutes can be added to the osmotic medium to obtain minimally processed products that can be stored at refrigerated temperatures. Nevertheless, it is important to consider that in addition to affecting the compositional and nutritional profile, they can affect the tissue metabolism, which can have consequences on the final product stability and shelf-life. Various authors have observed a reduction in the respiration rate of osmotically dehydrated mangoes, strawberries, pineapples and kiwifruit (Castelló et al., 2010; Moraga et al., 2009; Torres et al., 2008). Nevertheless, after a few days of storage, the respiratory quotient is generally observed to increase, as a result of the development of fermentative routes, which is an optional metabolic pathway triggered by osmotic stress.

Salvatori and Alzamora (2000) found that a $25 \%$ w/w sucrose solution can cause vesciculation and rupture of cell membranes in apple tissue. According to Mavroudis et al. (2004), few layers of cells on the surface are expected to die upon osmotic treatment, while plasmolysis and shrinkage occur in the remaining tissue. In a previous study, the authors found that $40 \% \mathrm{w} / \mathrm{w}$ sucrose treatment generally preserved the viability of apple cells, which only slightly affected the cell structure observed by fluorescence microscopy and the water distribution within the cells, as observed by time domain nuclear magnetic resonance (TD-NMR) (Mauro et al., 2016).

For different fruit species types, calcium can decrease the metabolic activity of tissue as well as the respiration rate (Castelló et al., 2010; Lester, 1996; Luna-Guzmán et al., 1999), which potentially enhances the product stability during storage, especially considering that a lower respiration rate may lead to a longer shelf life. In addition, $\mathrm{Ca}^{2+} \mathrm{can}$ affect the membrane and cell wall structure and functioning (Maurel, 2007; Peiter et al., 2005).

On the other hand, the presence of AA can cause serious injury to the cellular structure, as has been previously reported by Mauro et al. (2016), who observed a loss in the capacity to retain FDA colorant due to cell membrane damage following exposure to OD in a sucrose-ascorbic acid solution. As the AA concentration increased from 0 up to $2 \%$, a loss of vitality was detected.

Rocculi et al. (2005) found a higher metabolic activity in potato tissue upon dipping treatments with citric and ascorbic acid, suggesting that AA solution can promote a stress response in specific fresh-cut vegetable tissues, as well as an acceleration of their endogenous metabolic activity, which was confirmed by a higher $\mathrm{O}_{2}$ consumption according to head space gas determination. Limbo and Piergiovanni (2007) detected an increase in the respiration rate of sliced potatoes that were subjected to dipping treatment with $2.5 \%$ AA. However, when the AA concentration was $5 \%$, the respiration rate decreased.

Isothermal calorimetry has been recognized as a useful tool for assessing metabolic responses of various plant tissues to wounding stress (Wadsö et al., 2004), dipping treatment (Rocculi et al., 2005), thermal treatments (Gómez et al., 2004) and OD (Panarese et al., 2012).
Generally, when a tissue is wounded, certain signal paths are triggered, and the plant starts a number of protective processes that increase the produced metabolic heat (Wadsö et al., 2004). As reported by Gómez et al. (2004), after wounding, the energy released by the cellular tissue corresponds to the sum of that from the 'basic' cell metabolic activity and of that originating from wounding stress that is produced by the cells near the cut surface. Some of the processes that occur after wounding are aimed at membrane restoration and strengthening of cell walls by cells close to the site of injury (Rolle and Chism, 1987). A progressive reduction in the metabolic heat production during OD in kiwifruit slices was observed by Panarese et al. (2012) using isothermal calorimetry. The authors suggested that the decrease was due to a reduction in the cell viability that was induced by osmotic stress. Finally, the metabolic response of fruit tissues to OD was found to depend on the botanical origin, exerted osmotic pressure (Ferrando and Spiess, 2001; Mavroudis et al., 2004) and physiological state because loss of membrane integrity upon ripening that increases the permeability then makes the tissue more sensitive to osmotic stress (Panarese et al., 2012).

This study evaluated the effects of the addition of calcium lactate (CaLac) and ascorbic acid on sucrose osmotic solutions, mass transfer kinetics and raw endogenous metabolic response (respiration and heat production) of the tissue. The obtained information can be very useful for investigating the potential stability of minimally processed apples.

\section{Materials and methods}

\subsection{Raw materials}

Apples (Malus domestica Borkh; $30 \mathrm{~kg}$ ) of the Cripps Pink variety, popularly known by the brand name Pink Lady (de Castro et al., 2008), were bought at the local market and stored at $5 \pm 1^{\circ} \mathrm{C}$ for 2 weeks, during which the experimental research was performed. Apples were characterized by an average weight of $234 \pm 18 \mathrm{~g}$ and soluble solid content of $13.4 \pm 0.3 \mathrm{~g} / 100 \mathrm{~g}$. From the central part of the mesocarp fruit, cylindrical samples (8-mm diameter, 40-mm length) were cut with a manual cork borer and a manual cutter designed for the purpose. For osmotic treatments, commercial sucrose (refined sugar, Eridania Italia Spa, Italy), L-ascorbic acid (Shandong Luwei Pharmaceutical Co., China) and calcium lactate (calcium-Llactate 5-hydrate powder, PURACAL ${ }^{\circledR}$ PP Food, Corbion PURAC, Netherlands) were used.

\subsection{Osmotic dehydration}

OD was performed at $25{ }^{\circ} \mathrm{C}$ using four different osmotic solutions (w/w): $40 \%$ sucrose (Suc), $40 \%$ sucrose $+4 \%$ calcium lactate (Suc-CaLac), $40 \%$ sucrose $+2 \%$ ascorbic acid (Suc-AA) and $40 \%$ sucrose $+4 \%$ calcium lactate $+2 \%$ ascorbic acid (SucCaLac-AA).

Approximately $100 \mathrm{~g}$ of apple cylinders were weighed for each treatment time $(0.5,1,2$ and $4 \mathrm{~h})$ and placed in mesh baskets that were immersed in $4.5 \mathrm{~kg}$ of aqueous osmotic solution with a syrup-to-fruit ratio of approximately 15:1 (w/w) to avoid changes in the concentration of the solution during the treatment. Through an impeller of a mechanical stirrer, the cylindrical baskets were continuously rotated. The rotational speed $(0.2 \mathrm{~g})$ was experimentally determined to assure negligible external resistance to mass transfer. Two baskets were prepared for each process time.

After each treatment time, samples were removed from the solution, rinsed with distilled water, blotted with absorbing paper, and weighed. Subsequently, cylinders were placed in glass sealed ampoules to measure the endogenous metabolic heat production with isothermal calorimetry over $16 \mathrm{~h}$, which 
was followed by the determination of the $\mathrm{O}_{2}$ and $\mathrm{CO}_{2}$ levels on ampoule headspaces.

Total and soluble solid contents were determined in triplicate immediately after treatment. Samples for calcium and ascorbic acid analyses were freeze-dried.

\subsection{Analytical methods}

The moisture content of fresh and osmotically dehydrated samples was gravimetrically determined, in triplicate, by drying cylindrical apple samples at $70^{\circ} \mathrm{C}$ until a constant weight was reached. Soluble solid content was determined at $20^{\circ} \mathrm{C}$ by measuring the refractive index with a digital refractometer (PR1, Atago, Japan) that was calibrated with distilled water.

\subsubsection{Ascorbic acid}

Ascorbic acid was determined by HPLC analysis according to the method described by Odriozola-Serrano et al. (2007). Briefly, approximately $0.5 \mathrm{~g}$ of freeze-dried sample was added to $10 \mathrm{ml}$ of meta-phosphoric acid $(62.5 \mathrm{mM})$ and sulfuric acid (5 mM) solution, which was vortexed for $2 \mathrm{~min}$ and centrifuged at $10,000 \times g$ for $10 \mathrm{~min}$ at $4{ }^{\circ} \mathrm{C}$. The supernatant was directly used for the fresh sample and diluted tenfold for the impregnated samples; it was then filtered through a $0.45 \mu \mathrm{m}$ nylon filter. The HPLC system LC-1500 (Jasco, Carpi, MO, Italy) was equipped with a diode array UV/Vis detector. A reverse-phase C18 Kinetex (Phenomenex Inc., Torrance, CA, USA) stainless steel column $(4.6 \mathrm{~mm} \times 150 \mathrm{~mm})$ was used as the stationary phase. A Jasco AS-2055 Plus autosampler was used to introduce samples into the column. The mobile phase was a $0.01 \%$ solution of sulfuric acid that was adjusted to a $\mathrm{pH}$ of 2.6. The flow rate was fixed at $1.0 \mathrm{ml} / \mathrm{min}$ at room temperature. Data were processed with ChromNAV software (ver. 1.16.02) from Jasco. The ascorbic acid content was quantified at $245 \mathrm{~nm}$ through a standard calibration curve that was set up using an ascorbic acid solution between 0.5 to $30 \mathrm{ppm}$. The determination was performed in triplicate.

\subsubsection{Calcium}

The calcium concentration was determined using a flame atomic absorption spectrophotometer (Model A Analyst 400, Perkin Elmer, Santa Clara, California, USA) with a lumina hollow cathode lamp (Perkin Elmer) based on the adapted methodology of AOAC (2002). Briefly, approximately $6 \mathrm{~g}$ of freeze-dried, untreated samples and $2 \mathrm{~g}$ of freeze-dried treated samples, were weighed in a $50 \mathrm{ml}$ glazed, porcelain crucible; placed in a muffle furnace and heated up to $550^{\circ} \mathrm{C}$ until complete ignition. After cooling in desiccators, the ash was dissolved in $20 \mathrm{ml}$ (fresh samples) or $30 \mathrm{ml}$ (treated samples) of $\mathrm{HCl}(0.1 \mathrm{M})$; then, the solutions were appropriately diluted with $0.1 \mathrm{M} \mathrm{HCl}$. A calibration curve of the absorbance versus ppm of calcium was established using standard calcium solutions between 2 to $20 \mathrm{ppm}$. The initial sample level and subsequent dilution permits to obtain solutions with a concentration that was suitable to the standard solutions used for establishing a calibration curve of absorbance versus ppm of calcium (2-20 ppm). The determination was performed in triplicate.

\subsubsection{Metabolic heat production}

Two fresh cylindrical samples (8-mm diameter, 40-mm length) and three osmotically dehydrated samples were placed in $20 \mathrm{ml}$ glass ampoules and sealed with a teflon coated rubber seal and an aluminium crimp cap. Three replicates for each sample were performed. The rate of heat production was continuously measured in a TAM air isothermal calorimeter (Thermometric AB, Järfälla, Sweden) with a sensitivity (precision) of $\pm 10 \mu \mathrm{W}$ (Wadsö and Gómez Galindo, 2009). This instrument contains eight twin calorimeters in which each sample is inserted with its own reference, and the measured signal is the difference between the sample and reference signals. The reference has to be a material that does not produce any heat, but it is characterized by thermal properties that are similar to the sample. For this, water was chosen as the reference material and its quantity in each reference ampoule $\left(m_{w}^{\circ}\right)$ was previously determined based on the average composition of the samples and on the heat capacities $\left(\mathrm{Jg}^{-1} \mathrm{~K}^{-1}\right)$ of water $\left(C_{w}\right)$ and total solids $\left(C_{\mathrm{TS}}\right)$, as in the following equation:

$m_{w}^{o}=\frac{C_{T S} \cdot m_{T S}+C_{w} \cdot m_{w}}{C_{w}}$

where $m_{T S}$ is the dry matter content $(\mathrm{g})$ and $m_{w}$ is the water content of the fruit sample (g), and the average heat capacity of the total solids of the apple samples was assumed to be $1 \mathrm{Jg}^{-1} \mathrm{~K}^{-1}$. The analysis was performed at $10^{\circ} \mathrm{C}$ for $16 \mathrm{~h}$. The first $4 \mathrm{~h}$ of analysis were discarded because of the instability of the signal due to the loading and conditioning of samples.

\subsubsection{Respiration rate}

Immediately after the ampoules were discharged from the calorimeters, the $\mathrm{O}_{2}$ and $\mathrm{CO}_{2}$ percentages were measured in the ampoule headspaces by a check point gas analyser $\mathrm{O}_{2} / \mathrm{CO}_{2}$ mod. MFA III S/L (Witt-Gasetechnik, Witten, Germany). The apparatus has a paramagnetic sensor for $\mathrm{O}_{2}$ and a mini-IR spectrophotometer for $\mathrm{CO}_{2}$ detection. The instrument was calibrated with $\mathrm{O}_{2}$ and $\mathrm{CO}_{2}$ air percentages.

The respiration rate was calculated as mol of consumed $\mathrm{O}_{2}\left(\mathrm{RR}_{\mathrm{O}_{2}}\right)$ or produced $\mathrm{CO}_{2}\left(\mathrm{RR}_{\mathrm{CO}_{2}}\right) \mathrm{h}^{-1} \mathrm{~g}^{-1}$ according to the following equations:

$R R_{\mathrm{O}_{2}}=\frac{\mathrm{V}_{\text {head }} \cdot \frac{\left(20.8-\mathrm{O}_{2, \text { head }}\right)}{100} \cdot \mathrm{P}}{\mathrm{t} \cdot \mathrm{m} \cdot \mathrm{R} \cdot \mathrm{T}}$

$R R_{\mathrm{CO}_{2}}=\frac{\mathrm{V}_{\text {head }} \cdot \frac{\% \mathrm{CO}_{2, \text { head }}}{100} \cdot \mathrm{P}}{\mathrm{t} \cdot \mathrm{m} \cdot \mathrm{R} \cdot \mathrm{T}}$

where $V_{\text {head }}$ represents the ampoule headspace volume $\left(\mathrm{dm}^{3}\right)$, $\% \mathrm{O}_{2 \text {,head }}$ and $\% \mathrm{CO}_{2 \text {,head }}$ refer to molar gases percentages in the ampoule headspace at time $t(h), m$ is the sample mass $(\mathrm{g}) ; R$ is the gas constant $\left(8.314472 \mathrm{dm}^{3} \mathrm{kPa} \mathrm{K}^{-1} \mathrm{~mol}^{-1}\right), \mathrm{P}$ is the pressure $(101.325 \mathrm{kPa})$ and $\mathrm{T}$ is the absolute temperature $(283.15 \mathrm{~K})$.

\subsection{Osmotic dehydration kinetics}

Mass transfer of water, sucrose, calcium and ascorbic acid during the osmotic process was modelled according to the model proposed by Peleg (1988) to describe moisture sorption curves and was further used by Palou et al. (1994) to model OD, as follows:

$\Delta w_{k}=w_{k, t}-w_{k, 0}=-\frac{t}{k_{1}+k_{2} t}$

where $w_{k}$ is the mass fraction ( $\mathrm{g} \mathrm{g}^{-1}$ total mass) of the following $k$ species: water $\left(w_{w}\right)$, sucrose $\left(w_{\text {Suc }}\right)$, calcium $\left(w_{\mathrm{Ca}^{2+}}\right)$ or ascorbic acid $\left(w_{A A}\right)$ at time $0\left(w_{k, 0}\right)$ and time $t\left(w_{k, t}\right)$. The constants of Peleg's model are $k_{1}\left[\mathrm{~s}\left(\mathrm{gg}^{-1} \text { total mass }\right)^{-1}\right]$ and $k_{2}$ [1 $\left(\mathrm{gg}^{-1}\right.$ total mass $)^{-1}$. This kinetic model permits, by calculating the inverse of the two constants, to obtain the initial $(t=0)$ rate 
of mass transfer $\left(1 / k_{1}\right)$ and the mass fraction at equilibrium $(t \rightarrow \infty)$ conditions $\left(w_{k, e q}=w_{k, 0} \pm 1 / k_{2}\right)$ (Sacchetti et al., 2001).

\subsection{Statistical analysis and fitting}

The significance of the treatments was statistically evaluated by analysis of variance (ANOVA) and comparison of means using the Tukey's post-hoc test that was applied at a 5\% level of significance.

The Peleg's model was fitted to the experimental data using the Levenberg-Marquardt algorithm for the least-square estimation of the non-linear parameters (Marquardt, 1963). The fitting efficiency was evaluated by the coefficient of determination $\left(R^{2}\right)$ and the relative root mean square error (RRMSE); the latter was evaluated according to Eq. (5):

$\operatorname{RRMSE}(\%)=\sqrt{\frac{1}{N} \sum_{n=1}^{N}\left(\frac{y_{\text {obs }}-y_{\text {calc }}}{y_{\text {calc }}}\right)^{2}} \cdot 100$

where $y_{o b s}$ represents the observed value, $y_{\text {calc }}$ the calculated value and $N$ the number of observations.

\section{Results and discussion}

\subsection{Osmotic dehydration kinetics}

The Peleg's equation (Eq. (4)) was used to model the kinetics of water loss and solute uptake during OD. Constants of the Peleg's equation ( $k_{1}$ and $\left.k_{2}\right)$ and their inverse and equilibrium concentrations are reported in Table 1 . The predictive capability of the Peleg's model can be observed in Fig. 1, which compares the observed and calculated values of the mass fraction, which is expressed as a function of the process time, for water (a), sucrose (b), calcium (c) and ascorbic acid (d).

In general, the model showed a good fit with the experimental data, as high $R^{2}$ values and low RRMSE were found (Table 1), confirming its suitability for describing mass transfer phenomena in OD, as reported by Palou et al. (1994). The same model was also successfully applied by other researchers, such as Sacchetti et al. (2001).

Regarding Table 1, it can be observed that the initial rate of dehydration was increased by the presence of $\mathrm{Ca}^{2+}$ and AA in the osmotic solution, as higher $1 / k_{1}$ values were found for Suc-CaLac, Suc-AA and Suc-CaLac-AA treatments compared to the one with only sucrose in the solution. As reported in Fig. 1a, the presence of calcium in both Suc-CaLac and SucCaLac-AA solutions promoted a higher reduction in the water content than the treatments without $\mathrm{Ca}^{2+}$. Contrary to $\mathrm{Ca}^{2+}$, the presence of AA in the sucrose solution (Suc-AA treatment) caused only a slight depletion in the water content. In addition, the equilibrium water contents, calculated on the basis of the parameter $k_{2}$, were more affected by $\mathrm{Ca}^{2+}$, showing lower values than the other treatments (Table 1). It should be noted that when the osmotic solution contained both $\mathrm{Ca}^{2+}$ and $\mathrm{AA}$ solutes, the equilibrium water content was reduced to the lowest value $\left(0.6428 \mathrm{gg}^{-1}\right.$, Table 1$)$, which corresponds to the lowest water activity of all solutions. The water activities were $0.962 \pm 0.002$ for Suc, $0.953 \pm 0.001$ for Suc-CaLac, $0.954 \pm 0.001$ for Suc-AA and $0.944 \pm 0.004$ for Suc-CaLac-AA osmotic solutions. Conversely, despite the differences between the initial rates of water transfer found for the Suc and Suc-AA treatments (Table 1) as well as between the water activities of these two solutions, their equilibrium water levels were quite sim-
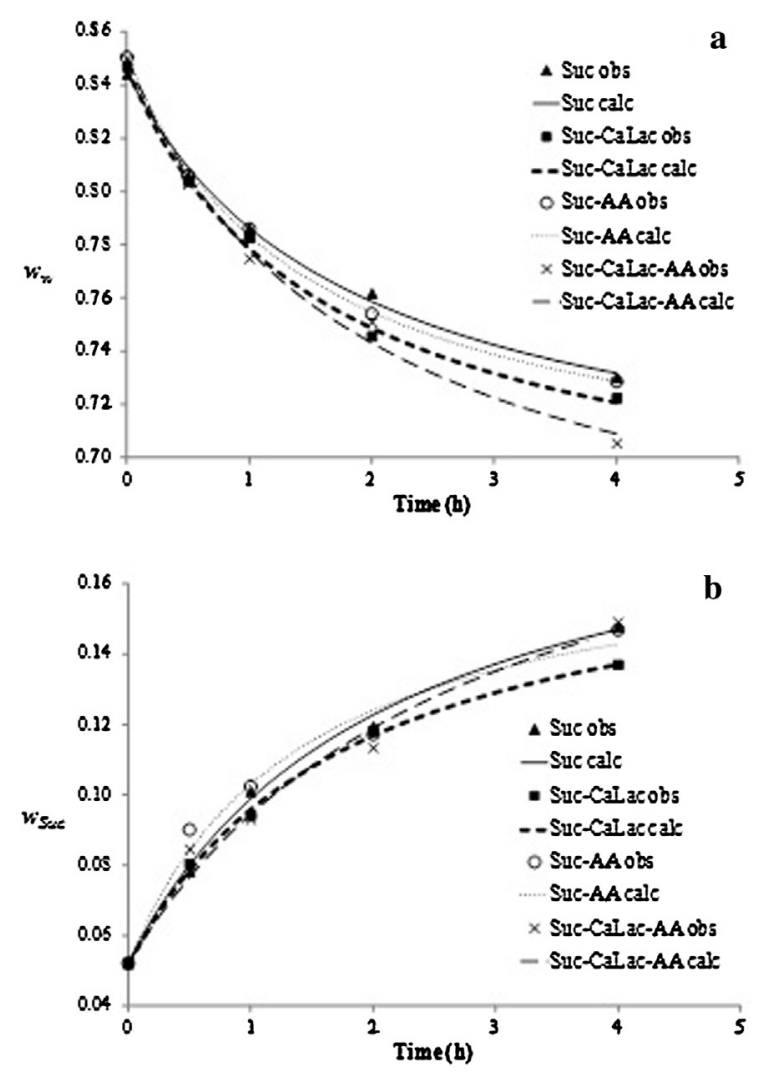

C
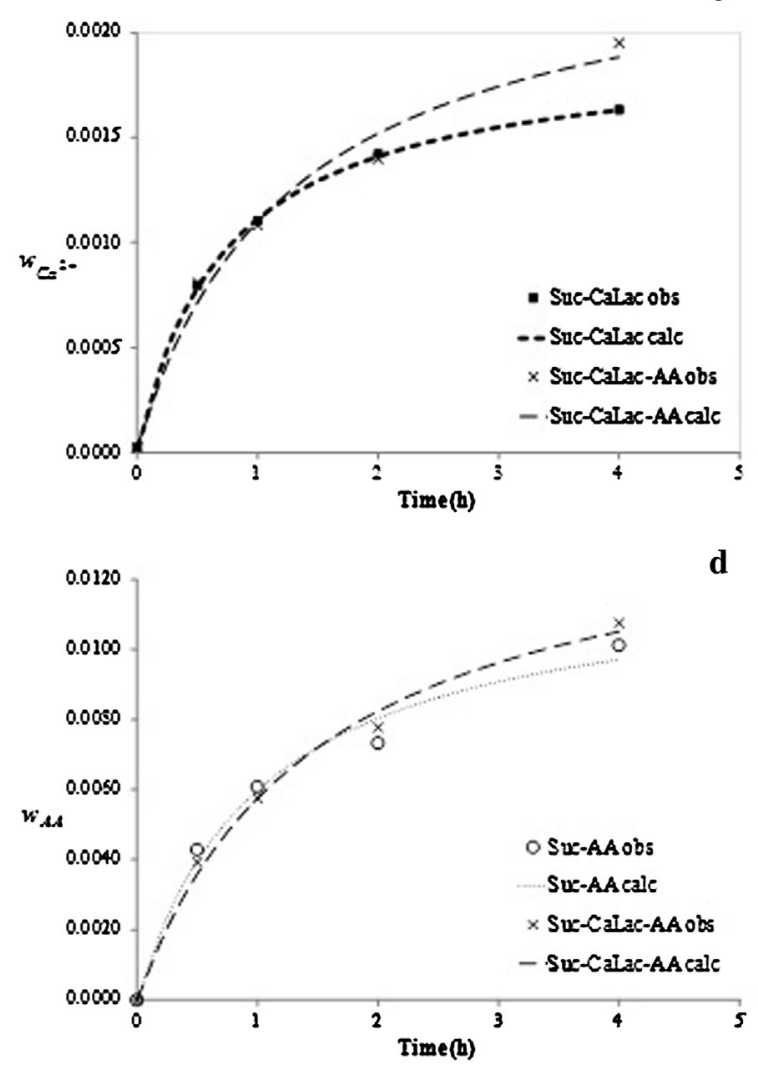

Fig. 1 - Comparison between the observed (obs) and calculated (calc) mass fraction of water (a), sucrose (b), calcium (c) and ascorbic acid (d) according to Peleg's model (Eq. (4)), in $\mathrm{g} \mathrm{g}^{-1}$ total mass, for the different treatments. 
Table 1 - Kinetic model of water, sucrose, calcium and ascorbic acid transfer in each osmotic solution according to Peleg's model (Eq. (4)) and equilibrium content ( $\mathrm{g} \mathrm{g}^{-\mathbf{1}}$ total mass).

\begin{tabular}{|c|c|c|c|c|c|c|c|c|c|c|c|}
\hline Solution & $k_{1}(\mathrm{~s})$ & SD & p-Level & $1 / k_{1} \times 10^{3}\left(s^{-1}\right)$ & $\begin{array}{l}k_{2}\left(\mathrm{~g}_{\text {total }}\right. \\
\text { mass g }^{-1} \text { ) }\end{array}$ & SD & p-Level & $\begin{array}{l}1 / k_{2} \times 10^{3}(g \\
\text { total } \\
\left.\text { mass } g^{-1}\right)^{-1}\end{array}$ & $R^{2}$ & RRMSE (\%) & $\begin{array}{l}w_{k, e q}\left(\mathrm{gg}^{-1}\right. \\
\text { total mass) }\end{array}$ \\
\hline & & & & & Water & & & & & & \\
\hline Suc & 11.18 & 0.78 & $<0.001$ & 89.45 & 6.10 & 0.33 & $<0.001$ & 163.90 & 0.997 & 3.8 & 0.6802 \\
\hline Suc-CaLac & 9.12 & 0.64 & $<0.001$ & 109.70 & 5.68 & 0.28 & $<0.001$ & 176.09 & 0.997 & 3.1 & 0.6708 \\
\hline Suc-AA & 8.93 & 0.46 & $<0.001$ & 112.00 & 5.98 & 0.21 & $<0.001$ & 167.26 & 0.998 & 3.1 & 0.6832 \\
\hline Suc-CaLac-AA & 9.10 & 1.07 & $<0.01$ & 109.92 & $\begin{array}{l}4.83 \\
\text { Sucrose }\end{array}$ & 0.45 & $<0.01$ & 206.88 & 0.992 & 5.3 & 0.6428 \\
\hline Suc & 14.51 & 1.32 & $<0.01$ & 68.92 & 6.92 & 0.54 & $<0.001$ & 144.54 & 0.998 & 3.8 & 0.1967 \\
\hline Suc-CaLac & 14.59 & 1.53 & $<0.001$ & 68.53 & 8.08 & 0.64 & $<0.001$ & 123.79 & 0.998 & 3.2 & 0.1759 \\
\hline Suc-AA & 11.49 & 2.18 & 0.01 & 87.05 & 8.13 & 1.01 & $<0.01$ & 123.03 & 0.980 & 8.60 & 0.1752 \\
\hline Suc-CaLac-AA & 17.36 & 3.17 & 0.01 & 57.62 & $\begin{array}{l}6.25 \\
\text { Calcium }\end{array}$ & 1.19 & 0.01 & 160.02 & 0.979 & 12.0 & 0.2122 \\
\hline Suc-CaLac & 392.99 & 7.40 & $<0.001$ & 2.54 & 523.45 & 4.31 & $<0.001$ & 1.91 & 1.000 & 0.7 & 0.0019 \\
\hline Suc-CaLac-AA & 524.34 & 83.76 & $<0.01$ & 1.91 & $\begin{array}{l}408.00 \\
\text { Ascorbic acid }\end{array}$ & 40.04 & $<0.01$ & 2.45 & 0.986 & 7.0 & 0.0025 \\
\hline Suc-AA & 85.44 & 14.08 & $<0.01$ & 11.70 & 81.48 & 7.24 & $<0.01$ & 12.27 & 0.986 & 5.9 & 0.0123 \\
\hline Suc-CaLac-AA & 104.72 & 10.56 & $<0.01$ & 9.55 & 68.83 & 4.76 & $<0.001$ & 15.53 & 0.994 & 4.8 & 0.0145 \\
\hline
\end{tabular}

ilar. These discrepancies are related to the presence of AA, which can affect the cellular structure and thus influence the water and solutes transfer, as well as the equilibrium contents, as further discussed below. Effects promoted by $\mathrm{Ca}^{2+}$ and AA, however, can be better observed when also assessing the sucrose transfer.

The initial rates of sucrose mass transfer $\left(1 / k_{1}\right)$ found in all treatments were lower than the ones calculated for water (Table 1). This behaviour is expected in plant tissue because the cell wall porosity and selective permeability of the cellular membranes reduce the transport of larger molecules, such as sucrose, through the cell tissue. While the cell membranes remain intact, intracellular spaces occupied by protoplasts and vacuoles are unavailable to sucrose transport. Conversely, water can diffuse throughout the cell walls and membranes and occupy all liquid phases of the plant cell (Mauro and Menegalli, 2003). The addition of $\mathrm{Ca}^{2+}$ and AA had a variable and unexpected influence on sucrose transport. When only $\mathrm{Ca}^{2+}$ was added, the treatment promoted an increase in the initial rate of the water transfer, but did not cause any change in the initial rateof the sucrose transfer, in comparison with the Suc treatment (Table 1). Moreover, it can be seen that the Suc-CaLac treatment led to the lowest sucrose content after four hours of processing (Fig. 1b).

Conversely, the highest value of $1 / k_{1}$ corresponded to the Suc-AA treatment. However, the addition of AA affected the behaviour of the sucrose content with time in both Suc-AA and Suc-CaLac-AA treatments, which sharply increased after $2 \mathrm{~h}$ of processing, as shown in Fig. 1b. Moreover, because of this change in the trend of these curves, the fitting efficiency worsened, as confirmed by the highest RRMSE values in Table 1 , $8.6 \%$ for Suc-AA and $12 \%$ for Suc-CaLac-AA. The worst fittings were related to the presence of AA that would have caused damage to the structure of cell walls and cellular membranes, changing transport during OD. The effects of AA on the microstructure of apple tissue and water distribution within the different cellular compartments changed the cell membranes permeability, as reported in a previous study (Mauro et al., 2016). In fact, AA can affect cellular tissue in different ways. Several studies have evaluated the role of AA in plant tissues that undergo stress; however, little is known regarding the mechanisms that explain its effects when plant tissues are not exposed to stress, as reported by Qian et al. (2014), who observed severe damage in the cellular structure of Arabidopsis thaliana seedlings that were exposed to exogenous AA. Additionally, an increase in the cell wall porosity is also expected because of the medium acidification (Zemke-White et al., 2000).

In addition, discrepancies were more visible in the SucCaLac-AA treatment, which presented the lowest initial rate $1 / k_{1}$ and the highest equilibrium value of $0.2122 \mathrm{gg}^{-1}$ (Table 1 ). The poor fittings related to the presence of AA in osmotic solutions added some uncertainty to the equilibrium content calculated for the Suc-AA and Suc-CaLac-AA treatments.

During OD, damages in the tissue promoted by the solution components and/or by the dehydration could release enzymes and cause depolymerisation, solubilisation and demethylation of pectins. Pectin, an important component of the primary cell wall, is mainly formed by homogalacturonan blocks. In the presence of divalent cations, such as $\mathrm{Ca}^{2+}$ and, depending on the degree of methylesterification and the distribution of the methyl-substituent groups, homogalacturonan can dimerise, reinforcing the cell adhesion and controlling the wall porosity (Bonnin and Lahaye, 2013). The calcium effect on firmness has been observed in various fruit tissues that undergo $\mathrm{OD}$ in the presence of calcium salts, and it has been attributed to reduction in the cell wall porosity and to the formation of calcium pectate (Mavroudis et al., 2012; Pereira et al., 2006; Silva et al., 2014a,b). Consequently, $\mathrm{Ca}^{2+}$ limited sucrose impregnation because of these interactions with pectin.

Good impregnation levels of both $\mathrm{Ca}^{2+}$ and AA were obtained, as shown in Fig. $1 \mathrm{c}$ and $\mathrm{d}$. The $\mathrm{Ca}^{2+}$ contents in both Suc-AA and Suc-CaLac-AA were very close until two hours of processing; afterwards, the impregnation quickly increased in those samples treated in Suc-CaLac-AA solution (Fig. 1c). Regarding the AA levels in Fig. 1d, a similar behaviour was observed, where, after two hours of processing, the AA impregnation tended to increase in both, = Suc-AA and Suc-CaLac-AA. The equilibrium concentrations of both $\mathrm{Ca}^{2+}$ and $\mathrm{AA}$ were also higher when samples were treated in Suc-CaLac-AA solution (Table 1). However, when $\mathrm{Ca}^{2+}$ was combined with AA, only after $2 \mathrm{~h}$ of $\mathrm{OD}$ was an increase in solute impregnation noticed, which is probably observed because the damage caused by AA surpassed the restraining effects of the cell structure impregnated with $\mathrm{Ca}^{2+}$ to the solute transport. 


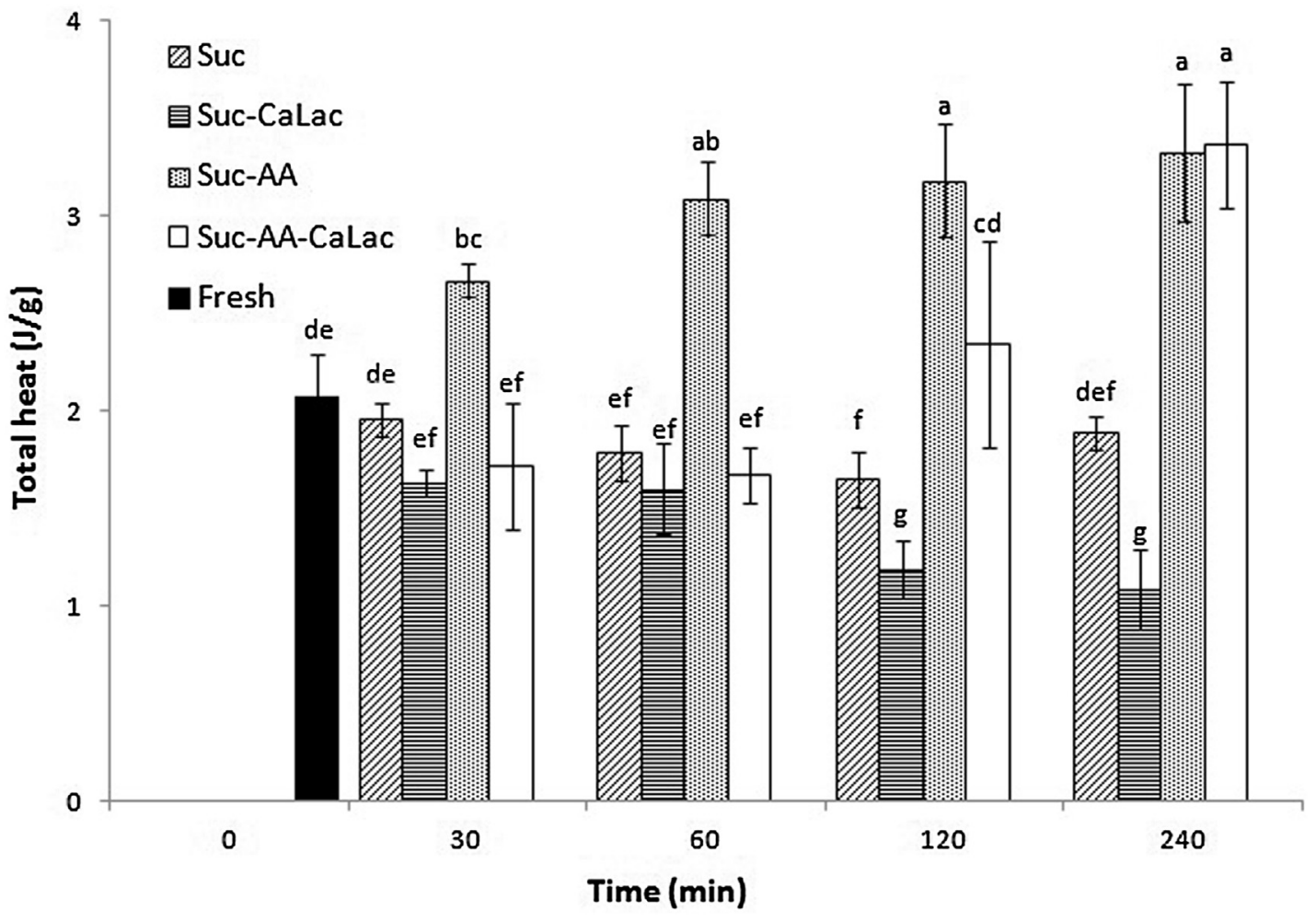

Fig. 2 - Total heat production $\left(\mathrm{J} / \mathrm{g}\right.$ ) of fresh and osmotically dehydrated samples during $16 \mathrm{~h}$ at $10^{\circ} \mathrm{C}$. Different letters indicate significant differences by the Tukey test at $\mathrm{p}<0.05$.

\subsection{Metabolic profiles}

The results of the total metabolic heat produced during $16 \mathrm{~h}$ at $10^{\circ} \mathrm{C}$, measured through isothermal calorimetry after osmotic treatments, were performed for 0, 30, 60, 120 and $240 \mathrm{~min}$ and are given in Fig. 2. Provided that the concentration of $\mathrm{O}_{2}$ and $\mathrm{CO}_{2}$ can also give useful information about tissue metabolism, after calorimetric analysis, the composition of the headspace of the vials was evaluated. The measured respiration rates $\left(\mathrm{RRO}_{2}\right.$ and $\left.\mathrm{RRCO}_{2}\right)$ are presented in Fig. 3.

As a consequence of Suc treatment, there was a slightly decreasing trend in metabolic heat production (Fig. 2), which was proportional to treatment time until two hours of processing, as well as a lower respiration rate compared to the fresh samples, both in terms of the $\mathrm{CO}_{2}$ produced and $\mathrm{O}_{2}$ consumed (Fig. 3). A partial loss of cell viability could be expected after OD treatment, even if the osmotic solution concentration was very low (Panarese et al., 2012). In a previous experiment (Mauro et al., 2016), cell viability was found to be preserved in apple tissue subjected to OD treatment with $40 \%$ sucrose solution, as observed by an FDA staining technique that allows for determination of the plasma membrane integrity. Conversely, neutral red staining revealed the incidence of plasmolysis that could help explain the decrease in the metabolic heat produced by the tissue. Salvatori and Alzamora (2000) found that a $25 \% \mathrm{w} / \mathrm{w}$ sucrose solution can cause vesciculation and rupture of the cell membranes in apple tissue. According to Mavroudis et al. (2004), only few layers of cells on the surface are expected to die upon osmotic treatment, while plasmolysis and shrinkage occur in the remaining tissue.

The presence of calcium in the osmotic solution caused a further decrease in the metabolic heat production. This result is in accordance with previous literature reports (Castelló et al., 2010; Luna-Guzmán et al., 1999), and it confirms the ability of calcium to slow down tissue metabolic activity and thus to enhance the stability of minimally processed fruit.

In various fruits, both whole and cut, an effect of calcium on respiration has been observed together with a reduction of ethylene production and general slowing of ripening and senescence (Lester, 1996; Saftner et al., 1999).

In particular, different explanations have been put forward for the reduction of the respiration rate: a protective osmotic effect due to the high salt concentration (Ferguson, 1984); an indirect effect on substrate transport from the alteration of the membrane permeability (Bangerth et al., 1972); the formation of a transient barrier between fruit and atmosphere that hinders gas exchange (Saftner et al., 1999); inhibition of plant aquaporins that regulate membrane permeability, causing an increase in the cytoplasmic ATP concentration that remains available for other biochemical routes (Kinoshita et al., 1995); and delay of senescence-related changes (Lester, 1996). At the same time, an excess of calcium has been related to a hastening of senescence because of damages to the plasma membrane structure and functionality.

Nevertheless, the effect of calcium on respiration has not been fully clarified to date. In the present experiment, the respiration rate values were similar to those of samples that were only dehydrated with sucrose, and they were only slightly lower after 30 and $240 \mathrm{~min}$, indicating that the reduction of heat produced could be related more to other biochemical phenomena than to the reduction of respiratory activity.

Conversely, the presence of AA in the osmotic solution promoted a drastic increase in the metabolic heat production as the treatment time increased up until 50\% compared to the fresh sample. This increase can probably be attributed to the physiological stress caused on the tissue, as already observed for sliced potatoes (Limbo and Piergiovanni, 2007; Rocculi et al., 2005). The damage to cellular structures, which is promoted by osmotic AA solution, can mainly be caused 


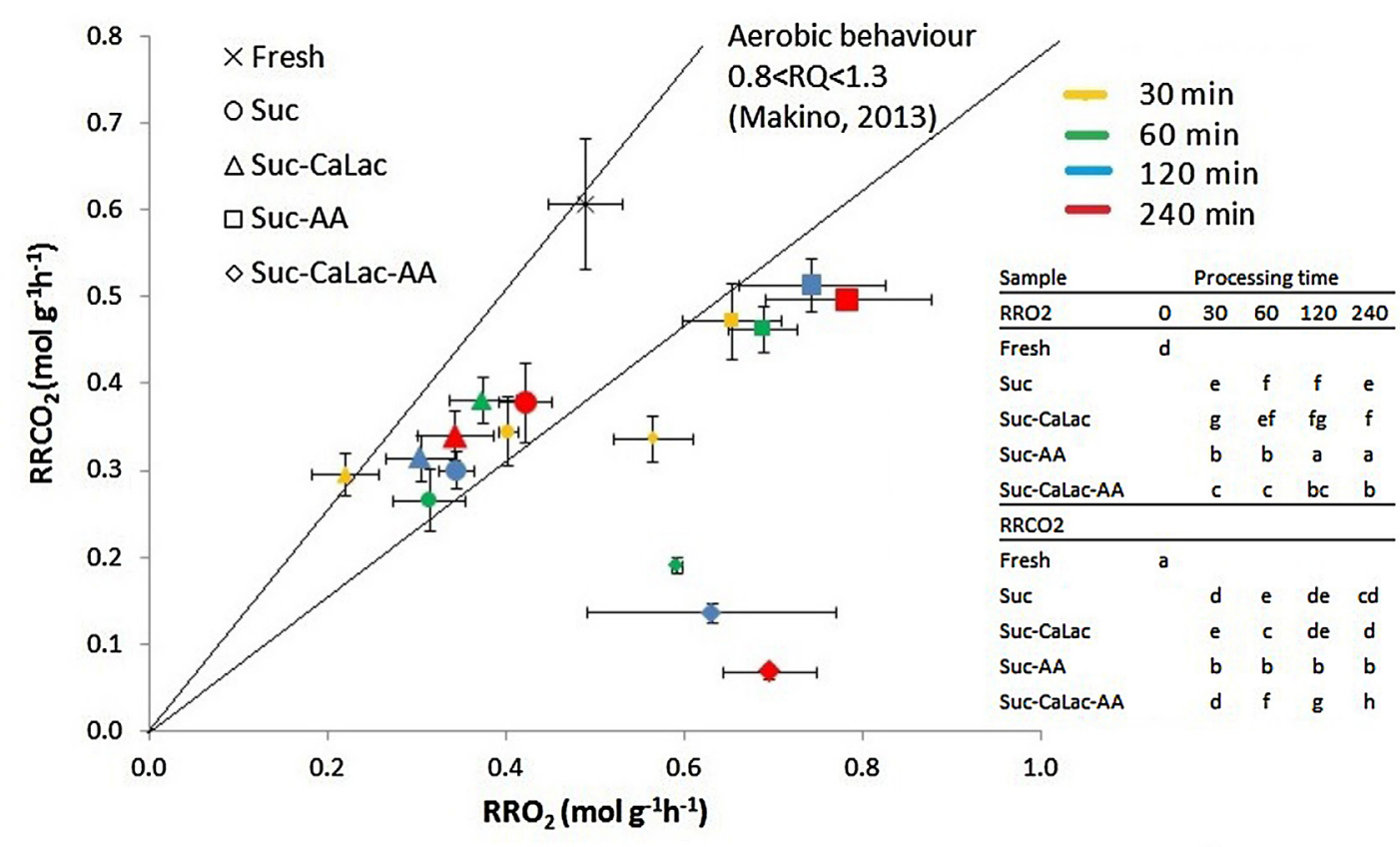

Fig. 3 - Respiration rates, expressed as the oxygen consumed $\left(\mathrm{RRO}_{2}\right)$ and carbon dioxide produced $(\mathrm{RRCO} 2)$, for treatment times of $30 \mathrm{~min}$ (yellow), $60 \mathrm{~min}$ (green), $120 \mathrm{~min}$ (blue) and $240 \mathrm{~min}$ (red). Error bars indicate standard deviation. Different letters in the auxiliary tables indicate significant differences according to the Tukey test at $\mathrm{p}<0.05$. (For interpretation of the references to color in this figure legend, the reader is referred to the web version of this article.)

by its lower $\mathrm{pH}$. At low $\mathrm{pH}$, plasma membrane ATPases in the tissue increase active $\mathrm{H}+$ pumping to address the excess of $\mathrm{H}+$ uptake, increasing the demand for respiratory energy. An ulterior $\mathrm{pH}$ decrease can also cause a decline in the respiration rates.

The combination of AA with Ca initially promoted a decrease in the heat production to a level that was lower than untreated samples; however, after $2 \mathrm{~h}$ of $\mathrm{OD}$, the metabolism sharply rose. This behaviour suggests that, during the first part of the treatment, calcium acted as stabilizer and reduced the metabolic activity of the tissue; however, as the treatment proceeded, a progressive damage to cellular structures occurred, which was probably related to the AA intake.

Conversely, for samples dehydrated in the presence of AA, both alone or in combination with CaLac, there was a noticeable change in the respiratory pathway, particularly in terms of the increased oxygen consumption compared with Suc and Suc-Ca samples (Fig. 3). The highest standard deviations were observed for $\mathrm{RRO}_{2}$ measurements in some AA samples. Although high variability was found in the respiration rates, reflecting the large natural variability of the raw and the treated material, useful indications were obtained. $\mathrm{CO}_{2}$ production was constant for all treatment times in AA samples, and there was a reduction of approximately $20 \%$ compared to the fresh tissue. The production was higher compared to in Suc and Suc-CaLac samples. Conversely, a noticeable $\mathrm{RRCO}_{2}$ decrease was verified in the Suc-CaLac-AA condition, which was proportional to the treatment time.

The respiratory quotient ( $R Q)$, calculated as the ratio $\mathrm{RRO}_{2} / \mathrm{RRCO}_{2}$, is an indicator of the respiration pathway adopted by tissues. The complete oxidation of glucose through the aerobic pathway produces an equal $\mathrm{CO}_{2}$ level compared to the $\mathrm{O}_{2}$ consumed; as a result, the respiratory quotient is 1. Variations in the RQ may depend on a different substrate used for respiration, such as malate or long chain fatty acids, although an increase in RQ generally indicates the onset of fermentative routes (Taiz and Zeiger, 1998). However, accord- ing to Makino (2013), an RQ in the range of $0.7-1.3$ could be considered an indicator of aerobic respiration. Approximately following this indication, it was possible to identify the samples that were characterized by aerobic metabolism in Fig. 3 that shows values of $\mathrm{RRO}_{2}$ and $\mathrm{RRCO}_{2}$ of samples at different OD times. In our experiment, fresh samples had an RQ value of 1.24, while in Suc and Suc-CaLac, RQ values were lower and closer to 1 , showing negligible anaerobic metabolism.

Anaerobic metabolism can be prompted by either low oxygen or high carbon dioxide concentrations in the environment that are, respectively, lower than $2 \%-5 \%$ and higher than 4\%-5\% (Cortellino et al., 2015; Iversen et al., 1989). Although these values were never exceeded, in some samples, and in particular in the fresh ones, the $\mathrm{CO}_{2}$ content was very close to this limit after $20 \mathrm{~h}$, which may have caused the development of some fermentative pathways, leading to an imbalance between $\mathrm{CO}_{2}$ production and $\mathrm{O}_{2}$ consumption in the tissue. This, in turn, increased the RQ. As a result, only samples treated with Suc-AA and Suc-CaLac-AA solutions seemed to have a non-aerobic response to the treatment.

As a consequence of OD, an increase in the RQ was observed by Torres et al. (2008) and by Castelló et al. (2010) on mango and strawberry tissues. Anaerobic metabolism is often found in plant tissue as a physiological response to stress conditions, such as dehydration, and as an optional metabolic pathway (Torres et al., 2008). While oxygen diffusion through the tissue decreases because of structural alteration in the cells as treatment proceeds, an increase of $\mathrm{CO}_{2}$ production has generally been observed by these authors. The oxygen consumed was attributed to the effort of some enzymatic systems to react to the stress caused by osmotic treatment (Lewicki et al., 2001). Conversely, Moraga et al. (2009) did not find changes from the presence of calcium lactate in the RQ of osmo-dehydrated grapefruit, although the respiration rate generally decreased.

In samples that were dehydrated in the presence of AA, a lower RQ was calculated and was found to decrease slightly by increasing the treatment time between 0.72 and 0.64 (data not 
shown). The combination of sucrose and ascorbic acid caused cellular damage to the tissue, and the effect on the plasmalemma and tonoplast was different and unclear, but there was a strong influence on tissue functionality (Mauro et al., 2016). When both AA and CaLac were used, the RQ decreased sharply, from 0.59 to 0.09 , as dehydration proceeded. This decrease is mainly due to the higher oxygen consumption observed compared to $\mathrm{CO}_{2}$ production.

It is important to note that the variation of the gas composition in the sample headspace could be from both the respiratory metabolism of the tissue and the presence of other enzymatic reactions. According to Igual et al. (2008), this $\mathrm{O}_{2}$ consumption can be considered as the "apparent" respiration rate. Because molecular oxygen can be used as substrate by many enzymes in plant tissue, it can contribute to the "apparent" respiration rate if measured in terms of oxygen consumption and not in terms $\mathrm{CO}_{2}$ production (Taiz and Zeiger, 1998). Concerning this particular issue, the effect of sugar, calcium and ascorbic acid on the complexity of fresh tissue enzymatic activity must be considered.

\section{Conclusions}

The investigated osmotic dehydration treatments showed different effects on the product in terms of both mass transfer phenomena during processing and metabolic activity of the apple tissue. The presence of calcium lactate (CaLac) and ascorbic acid (AA) affected the water and solute transport, which was attributed to changes in the cellular structure. Significant impregnation of solutes promoted by AA was related to severe damage caused to the cell structure, increasing spaces viable for solute transport. $\mathrm{Ca}^{2+}$ contributed to the improvement of dehydration and to limit the sucrose impregnation; however, in combination with AA, its capacity to restrain solute transport was diminished after $2 \mathrm{~h}$ of $\mathrm{OD}$, which was probably because of the excessive AA gain.

Metabolic heat production in samples treated in sucrose solutions was slightly lower than in untreated samples, and it was further reduced with calcium lactate (CaLac) addition. However, samples impregnated with ascorbic acid (AA) showed higher heat production because there was a metabolic response of the apple tissue to AA treatment. When combined with $\mathrm{Ca}^{2+}$, heat production decreased sharply to a level that was lower than untreated samples, except for those treated for $240 \mathrm{~min}$ (higher solid gain), which showed the highest heat production values. These results confirm previous findings, suggesting that AA solution can promote a stress response on specific fresh-cut vegetable tissues and an increase of their endogenous metabolic activity, which was further confirmed by a higher $\mathrm{O}_{2}$ consumption that was observed by head space gas determination.

To clarify the effect on enzymatic activity in apples that were osmotically dehydrated in sucrose, calcium and ascorbic acid osmotic solutions and the real influence of these phenomena on respiration pathways, further studies are warranted that can couple the calo-respirometric approach with metabolomic analytical techniques.

\section{Acknowledgments}

The authors acknowledge the financial support of the Italian Ministry for Education, Universities and Research (FIRB, Project RBFR100CEJ: Innovative approach for the study of fresh-cut fruit: qualitative, metabolic and functional aspects).

\section{References}

Ahmed, I., Qazi, I.M., Jamal, S., 2016. Developments in osmotic dehydration technique for the preservation of fruits and vegetables. Innov. Food Sci. Emerg. Technol. 34, 29-43.

Akbarian, M., Ghasemkhani, N., Moayedi, F., 2014. Osmotic dehydration of fruits in food industrial: a review. Int. J. Biosci. 4 (1), 42-57.

Anino, S.V., Salvatori, D.M., Alzamora, S.M., 2006. Changes in calcium level and mechanical properties of apple tissue due to impregnation with calcium salts. Food Res. Int. 39 (2), 154-164.

AOAC International, 2002. Official methods of analysis (OMA) of AOAC International, 17th ed, USA. Method number: 920.15. Available at http://www.eoma.aoac.org/.

Bangerth, F., Dilley, D.R., Dewey, D.H., 1972. Effect of postharvest calcium treatments on internal breakdown and respiration of apple fruits. J. Am. Soc. Hortic. Sci.

Barrera, C., Betoret, N., Fito, P., 2004. $\mathrm{Ca}^{2+}$ and $\mathrm{Fe}^{2+}$ influence on the osmotic dehydration kinetics of apple slices (var. Granny Smith). J. Food Eng. 65 (1), 9-14.

Bonnin, E., Lahaye, M., 2013. Contribution of cell wall-modifying enzymes to the texture of fleshy fruits. The example of apple. J. Serb. Chem. Soc. 78 (3), 417-427.

Castelló, M.L., Fito, P.J., Chiralt, A., 2010. Changes in respiration rate and physical properties of strawberries due to osmotic dehydration and storage. J. Food Eng. 97 (1), 64-71.

Cortellino, G., Gobbi, S., Bianchi, G., Rizzolo, A., 2015. Modified atmosphere packaging for shelf life extension of fresh-cut apples. Trends Food Sci. Technol. 46 (2, Part B), 320-330.

Cortellino, G., Pani, P., Torreggiani, D., 2011. Crispy air-dried pineapple rings: optimization of processing parameters. Procedia Food Sci. 1, 1324-1330.

de Castro, E., Barrett, D.M., Jobling, J., Mitcham, E.J., 2008. Biochemical factors associated with a $\mathrm{CO}_{2}$-induced flesh browning disorder of Pink Lady apples. Postharvest Biol. Technol. 48 (2), 182-191.

Ferguson, I.B., 1984. Calcium in plant senescence and fruit ripening. Plant Cell Environ. 7 (6), 477-489.

Fernandez, C.M.O., Mazzanti, G., LeMaguer, M., 2004. Development of methods to classify mass transfer behaviour of plant tissues during osmotic dehydration. Food Bioprod. Process. 82 (1), 49-53.

Ferrando, M., Spiess, W.E.L., 2001. Cellular response of plant tissue during the osmotic treatment with sucrose, maltose, and trehalose solutions. J. Food Eng. 49 (2), 115-127.

Ferrari, C.C., Carmello-Guerreiro, S.M., Bolini, H.M.A., Hubinger, M.D., 2010. Structural changes, mechanical properties and sensory preference of osmodehydrated melon pieces with sucrose and calcium lactate solutions. Int. J. Food Prop. 13 (1), 112-130.

Gómez, F., Toledo, R.T., Wadsö, L., Gekas, V., Sjöholm, I., 2004. Isothermal calorimetry approach to evaluate tissue damage in carrot slices upon thermal processing. J. Food Eng. 65 (2), 165-173.

Guiamba, I., Ahrné, L., Khan, M.A., Svanberg, U., 2016. Retention of $\beta$-carotene and vitamin $C$ in dried mango osmotically pretreated with osmotic solutions containing calcium or ascorbic acid. Food Bioprod. Process. 98, 320-326.

Igual, M., Castelló, M.L., Ortolá, M.D., Andrés, A., 2008. Influence of vacuum impregnation on respiration rate, mechanical and optical properties of cut persimmon. J. Food Eng. 86 (3), 315-323.

Iversen, E., Wilhelmsen, E., Criddle, R., 1989. Calorimetric examination of cut fresh pineapple metabolism. J. Food Sci. 54 (5), 1246-1249.

Kinoshita, T., Nishimura, M., Shimazaki, K.I., 1995. Cytosolic concentration of $\mathrm{Ca}^{2+}$ regulates the plasma membrane $\mathrm{H}^{+}$-ATPase in guard cells of fava bean. Plant Cell 7 (8), 1333-1342.

Lenart, A., 1996. Osmo-convective drying of fruits and vegetables: technology and application. Dry. Technol. 14 (2), 391-413. 
Lester, G., 1996. Calcium alters senescence rate of postharvest muskmelon fruit disks. Postharvest Biol. Technol. 7 (1), 91-96.

Lewicki, P.P., Gondek, E., Witrowa-Rajchert, D., Nowak, D., 2001. Effect of drying on respiration of apple slices. J. Food Eng. 49 (4), 333-337

Limbo, S., Piergiovanni, L., 2007. Minimally processed potatoes: Part 2. Effects of high oxygen partial pressures in combination with ascorbic and citric acid on loss of some quality traits. Postharvest Biol. Technol. 43 (2), 221-229.

Luna-Guzmán, I., Cantwell, M., Barrett, D.M., 1999. Fresh-cut cantaloupe: effects of $\mathrm{CaCl}_{2}$ dips and heat treatments on firmness and metabolic activity. Postharvest Biol. Technol. 17 (3), 201-213.

Makino, Y., 2013. Oxygen consumption by fruits and vegetables. Food Sci. Technol. Res. 19 (4), 523-529.

Marquardt, D.W., 1963. An algorithm for least-squares estimation of nonlinear parameters. J. Soc. Ind. Appl. Math. 11 (2), 431-441.

Maurel, C., 2007. Plant aquaporins: novel functions and regulation properties. FEBS Lett. 581 (12), 2227-2236.

Mauro, M.A., Dellarosa, N., Tylewicz, U., Tappi, S., Laghi, L., Rocculi, P., Rosa, M.D., 2016. Calcium and ascorbic acid affect cellular structure and water mobility in apple tissue during osmotic dehydration in sucrose solutions. Food Chem. 195, 19-28.

Mauro, M.A., Menegalli, F.C., 2003. Evaluation of water and sucrose diffusion coefficients in potato tissue during osmotic concentration. J. Food Eng. 57 (4), 367-374.

Mavroudis, N.E., Dejmek, P., Sjöholm, I., 2004. Osmotic-treatment-induced cell death and osmotic processing kinetics of apples with characterised raw material properties. J. Food Eng. 63 (1), 47-56.

Mavroudis, N.E., Gidley, M.J., Sjöholm, I., 2012. Osmotic processing: effects of osmotic medium composition on the kinetics and texture of apple tissue. Food Res. Int. 48 (2), 839-847

Moraga, M.J., Moraga, G., Fito, P.J., Martínez-Navarrete, N., 2009. Effect of vacuum impregnation with calcium lactate on the osmotic dehydration kinetics and quality of osmodehydrated grapefruit. J. Food Eng. 90 (3), 372-379.

Odriozola-Serrano, I., Hernández-Jover, T., Martín-Belloso, O., 2007. Comparative evaluation of UV-HPLC methods and reducing agents to determine vitamin $\mathrm{C}$ in fruits. Food Chem. 105 (3), 1151-1158.

Palou, E., Lopez-Malo, A., Argaiz, A., Welti, J., 1994. The use of Peleg's equation to model osmotic concentration of papaya. Dry. Technol. 12 (4), 965-978.

Panarese, V., Tylewicz, U., Santagapita, P., Rocculi, P., Dalla Rosa, M., 2012. Isothermal and differential scanning calorimetries to evaluate structural and metabolic alterations of osmo-dehydrated kiwifruit as a function of ripening stage. Innov. Food Sci. Emerg. Technol. 15, 66-71.

Peiter, E., Maathuis, F.J.M., Mills, L.N., Knight, H., Pelloux, J., Hetherington, A.M., et al., 2005. The vacuolar $\mathrm{Ca}^{2+}$-activated channel TPC1 regulates germination and stomatal movement. Nature 434 (7031), 404-408.

Peleg, M., 1988. An empirical model for the description of moisture sorption curves. J. Food Sci. 53 (4), 1216-1217.

Pereira, L., Ferrari, C., Mastrantonio, S., Rodrigues, A., Hubinger, M., 2006. Kinetic aspects, texture, and color evaluation of some tropical fruits during osmotic dehydration. Dry. Technol. 24 (4), 475-484.

Qi, H., LeMaguer, M., Sharma, S.K., 1998. Design and selection of processing conditions of a pilot scale contactor for continuous osmotic dehydration of carrots. J. Food Process Eng. 21 (1), 75-88.

Qian, H.F., Peng, X.F., Han, X., Ren, J., Zhan, K.Y., Zhu, M., 2014. The stress factor, exogenous ascorbic acid, affects plant growth and the antioxidant system in Arabidopsis thaliana. Russ. J. Plant Physiol. 61 (4), 467-475.

Ramallo, L.A., Mascheroni, R.H., 2010. Dehydrofreezing of pineapple. J. Food Eng. 99 (3), 269-275.

Robbers, M., Singh, R., Cunha, L.M., 1997. Osmotic-convective dehydrofreezing process for drying kiwifruit. J. Food Sci. 62 (5), 1039-1042.

Rocculi, P., Romani, S., Dalla Rosa, M., Wadsö, L., Gómez, F., Sjöholm, M., 2005. Influence of pre-treatments on metabolism and wounding response of fresh cut potatoes evaluated with isothermal calorimetry. Int. Postharvest Symp. 682, 1833-1838.

Rolle, R.S., Chism, G.W., 1987. Physiological consequences of minimally processed fruits and vegetables. J. Food Qual. 10 (3) 157-177.

Sacchetti, G., Gianotti, A., Dalla Rosa, M., 2001. Sucrose-salt combined effects on mass transfer kinetics and product acceptability. Study on apple osmotic treatments. J. Food Eng. 49 (2), 163-173.

Saftner, R.A., Conway, W.S., Sams, C.E., 1999. Postharvest calcium infiltration alone and combined with surface coating treatments influence volatile levels, respiration, ethylene production, and internal atmospheres of 'Golden Delicious' apples. J. Am. Soc. Hortic. Sci. 124 (5), 553-558.

Salvatori, D., Alzamora, S.M., 2000. Structural changes and mass transfer during glucose infusion of apples as affected by blanching and process variables. Dry. Technol. 18 (1-2), 361-382.

Saputra, D., 2001. Osmotic dehydration of pineapple. Dry. Technol. 19 (2), 415-425.

Silva, K.S., Fernandes, M.A., Mauro, M.A., 2014a. Effect of calcium on the osmotic dehydration kinetics and quality of pineapple. J. Food Eng. 134, 37-44.

Silva, K.S., Fernandes, M.A., Mauro, M.A., 2014b. Osmotic dehydration of pineapple with impregnation of sucrose, calcium, and ascorbic acid. Food Bioprocess Technol. 7 (2), 385-397.

Taiz, L., Zeiger, E., 1998. Plant Physiology, 2nd ed. Sinauer, Sunderland, Massachussets, pp. 111-143.

Torres, J.D., Castelló, M.L., Escriche, I., Chiralt, A., 2008. Quality characteristics, respiration rates, and microbial stability of osmotically treated mango tissue (Mangifera indica L.) with or without calcium lactate. Food Sci. Technol. Int. 14 (4), 355-365.

Wadsö, L., Gomez, F., Sjöholm, I., Rocculi, P., 2004. Effect of tissue wounding on the results from calorimetric measurements of vegetable respiration. Thermochim. Acta 422 (1-2), 89-93.

Wadsö, L., Gómez Galindo, F., 2009. Isothermal calorimetry for biological applications in food science and technology. Food Control 20 (10), 956-961.

Zemke-White, W.L., Clements, K.D., Harris, P.J., 2000. Acid lysis of macroalgae by marine herbivorous fishes: effects of acid $\mathrm{pH}$ on cell wall porosity. J. Exp. Mar. Biol. Ecol. 245 (1), 57-68. 